\title{
USO INTRAMUSCULAR DA ASSOCIAÇÃO DE TILETAMINA E ZOLAZEPAM NA ANESTESIA DE TILÁPIAS-DO-NILO (Oreochromis niloticus)
}

\author{
Sofia Borin, ${ }^{1}$ Leandro Zuccolotto Crivelenti ${ }^{2}$ e Cirilo Antonio de Paula Lima ${ }^{3}$ \\ 1. Residente da área de Pequenos Animais da FCAV/UNESP. E-mail: sofiaborin_vet@yahoo.com.br \\ 2. Residente de Clínica e Cirurgia de Pequenos Animais da UNIFRAN, SP \\ 3. Professor doutor de Anestesiologia Veterinária da UFU/MG.
}

RESUMO

Dado o sucesso da associação anestésica de tiletamina e zolazepam (Zoletil $\left.{ }^{\circledR} 50\right)$ na anestesia de tilápias-do-nilo (Oreochromis niloticus) pela via intravenosa, objetivou-se com este experimento avaliar o emprego dessa associação administrada pela via intramuscular. Utilizaram-se trinta peixes, os quais foram separados em seis tratamentos com quatro repetições e um controle, testando-se as dosagens de 5, 10, 20, 30, 40 e $60 \mathrm{mg} / \mathrm{kg}$. Apesar de a associação anestésica nas doses entre 10 e $60 \mathrm{mg} / \mathrm{kg}$ ter acarretado sedação de graus leve a moderado após administração intramuscular, sugere-se que o uso da associação de tiletamina e zolazepam por essa via seja impróprio para procedimentos cruentos e algésicos, pois nenhuma dessas dosagens foi capaz de causar anestesia nessa espécie.

PALAVRAS-CHAVES: Anestesiologia, peixes, Zoletil ${ }^{\circledR} 50$.

\section{ABSTRACT}

\section{INTRAMUSCULAR USE OF TILETAMINE-ZOLAZEPAM ASSOCIATION IN THE ANESTHESIA OF NILE TILAPIA (Oreochromis niloticus)}

Once the anesthetic association of tiletamine and zolazepam (Zoletil $\left.{ }^{\circledR} 50\right)$ was successfully used in the anesthesia of Nile tilapias (Oreochromis niloticus) via intravenous, the aim of this experiment was to evaluate the use of this association via intramuscular. 30 fish separated into 6 treatments with 4 repetitions and 1 control group were used. The dosages of 5, 10, 20, 30, 40 and $60 \mathrm{mg} / \mathrm{kg}$ were tested. Even though the anesthetic association

KEYWORDS: Anesthesiology, fish, Zoletil ${ }^{\circledR} 50$.

\section{INTRODUÇÃO}

A fácil adaptação, tanto ao cultivo extensivo sem qualquer tecnologia empregada quanto ao sistema de criação em tanques-rede com rações completas e alta tecnologia de produção, fez da tilápia-do-nilo dosages between 10 and $60 \mathrm{mg} / \mathrm{kg}$ have caused sedation from slight to moderate levels after the intramuscular administration, it was possible to suggest that the use of tiletamine and zolazepam association through this via is not proper for bloody and algesic procedures, once none of those dosages were capable enough to provoke anesthesia in this species.

(Oreochromis niloticus) uma espécie de peixe bastante versátil (MEURER et al., 2002) e a mais cultivada em todo o mundo (BACCONI, 2003).

Sabe-se que alguns acidentes podem ocorrer se o peixe não estiver eficientemente imobilizado durante a realização de procedimentos rotineiros (biometria, 
injeções, coleta de materiais para análises, marcações) ou até mesmo cirurgias. Além do que, movimentos inadvertidos podem causar danos na superfície corporal e favorecer a ocorrência de doenças, podendo levá-los à morte (DURVILLE \& COLLET, 2001).

Dessa forma, autores aconselham o uso de anestésicos em diversos procedimentos, por mais superficiais e pouco cruentos que sejam, com o intuito de facilitar a manipulação por veterinários, evitar o estresse, prevenir danos à saúde e reduzir a mortalidade dos peixes (FANTONI et al., 2000; SLADY et al., 2001; SVOBODÁ et al., 2001; CUNHA et al., 2002).

Os anestésicos, de maneira geral, devem satisfazer algumas exigências, tais como rápido início de ação, apresentar larga margem de segurança e possibilitar ao peixe recuperação espontânea (SVOBODÁ et al., 2001). Sendo a combinação do cloridrato de tiletamina e cloridrato de zolazepam recomendada para atividades de contenção e manipulação de animais na natureza (SANTOS et al., 1999), neste trabalho buscou-se avaliar esta associação, administrada por via intramuscular e em diferentes dosagens, na anestesia de tilápias-do-nilo (Oreochromis niloticus).

\section{MATERIAL E MÉTODOS}

O projeto foi desenvolvido nas dependências do Núcleo de Pesquisa em Piscicultura (NUPEP) da Faculdade de Medicina Veterinária da Universidade Federal de Uberlândia, MG, Brasil, em outubro de 2005.

Para o protocolo de anestesia intramuscular, utilizaram-se trinta tilápias (Oreochromis niloticus) com peso médio de $100 \mathrm{~g} \mathrm{e} 17 \mathrm{~cm}$ de comprimento, as quais foram submetidas a 24 horas de jejum antes da realização do experimento. Os peixes foram divididos ao acaso em seis tratamentos com quatro repetições e um controle.

A associação de tiletamina e zolazepam (Zoletil ${ }^{\circledR}$ 50) foi administrada por via intramuscular profunda na musculatura dorsal, utilizando-se seringa de $1 \mathrm{~mL}$ e agulha 13 x 4,5 mm (Figura 1).

A distribuição dos tratamentos foi dividida em: $\mathrm{T} 1=5 \mathrm{mg} / \mathrm{kg} ; \mathrm{T} 2=10 \mathrm{mg} / \mathrm{kg} ; \mathrm{T} 3=20 \mathrm{mg} / \mathrm{kg} ; \mathrm{T} 4=30$ $\mathrm{mg} / \mathrm{kg}$; $\mathrm{T} 5=40 \mathrm{mg} / \mathrm{kg}$ e $\mathrm{T} 6=60 \mathrm{mg} / \mathrm{kg}$ de peso vivo. Para cada tratamento, utilizou-se um animal, controle $(p<0,001)$, que recebeu o mesmo equivalente em vo- lume da associação anestésica, porém de solução de cloreto de sódio a $0,9 \%$.

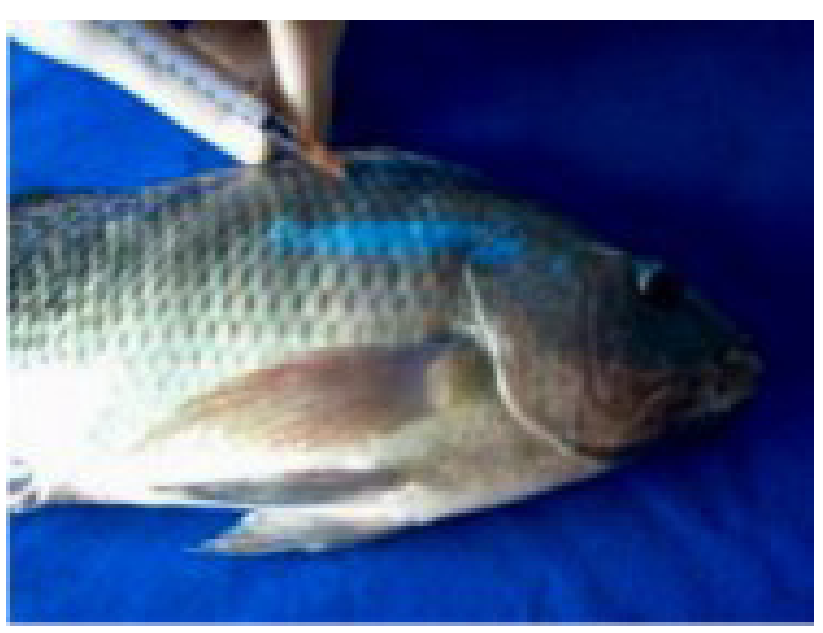

FIGURA 1. Aplicação da associação anestésica em tilápia-donilo (Oreochromis niloticus) pela via intramuscular profunda, na musculatura dorsal.

Os animais foram identificados por fio de algodão de cores diferentes $(\mathrm{T} 1=$ vermelho, $\mathrm{T} 2=$ azul, $\mathrm{T} 3=$ branco, $\mathrm{T} 4=$ roxo, $\mathrm{T} 5=$ amarelo e $\mathrm{T} 6=$ verde) fixados na nadadeira dorsal, por meio de perfuração por agulha cirúrgica romba. Identificaram-se os animais-controle de cada grupo com dois fios, um de cor salmão e o outro da cor do tratamento correspondente.

Imediatamente após a aplicação da associação anestésica, os animais foram transferidos para aquário de vidro com capacidade de $80 \mathrm{~L}$, para melhor visualização e avaliação da ação da medicação. Mantiveramse as características físico-químicas da água com temperatura de $26^{\circ} \mathrm{C}$ e $\mathrm{pH} 7,8$, conforme recomendado para a espécie (SVOBODÁ et al., 2001).

Como indicação do grau de depressão ocasionado pela medicação, foram observadas as seguintes mudanças comportamentais: desorientação, perda de equilíbrio, decúbito ventral, decúbito lateral, imobilização, perda dos movimentos das nadadeiras, parada respiratória. Classificou-se o nível de depressão em: 0 - nenhum efeito; 1 - sedação leve; 2- sedação moderada; 3- sedação profunda; 4- anestesia e 5- morte (McFARLAND \& KLONTZ, 1969) (Tabela 1).

Após a aplicação da medicação, foram gentilmente estimulados a nadar a cada cinco minutos duran- 
te uma hora, para avaliação dos efeitos da medicação (AGORAMOORTHY \& RUDRAN, 1994), e depois foram colocados juntos em um tanque de $500 \mathrm{~L}$, para posteriores avaliações num período de 72 horas.

TABELA 1. Caracterização dos níveis de depressão ocasionados pela utilização da associação de cloridrato de tiletamina e cloridrato de zolazepam em tilápias-do-nilo (Oreochromis niloticus)

\begin{tabular}{ll}
\hline \multicolumn{1}{c}{ Grau de depressão } & \multicolumn{1}{c}{ Mudança comportamental } \\
\hline $0-$ Nenhum efeito & Nenhuma \\
1 - Sedação leve & Desorientação, diminuição dos reflexos e dos movimentos das nadadeiras. \\
2 - Sedação moderada & Decúbito ventral, diminuição dos reflexos e dos movimentos das nadadeiras. \\
$3-$ Sedação profunda & Decúbito lateral, sem movimentos de nadadeira, porém reativo a estímulos. \\
$4-$ Anestesia & Decúbito lateral, sem movimentos de nadadeira e arresponsividade a estímulos. \\
$5-$ Morte & Parada dos movimentos operculares e respiratórios. \\
\hline
\end{tabular}

*Tabela elaborada com base nos dados de McFARLAND \& KLONTZ (1969).

\section{RESULTADOS}

Os resultados da avaliação dos peixes durante o processo de anestesia intramuscular encontram-se na Tabela 2.

Os peixes do tratamento 1 receberam $5 \mathrm{mg} /$ $\mathrm{kg}$ da associação anestésica $(0,01 \mathrm{~mL})$. Decorridos trinta minutos da aplicação da medicação, verificou- se ligeira diminuição nos movimentos da nadadeira dorsal quando comparados com o controle. Durante cinquenta minutos, os animais ficaram mais tranquilos, tendendo a manter-se no fundo do aquário, porém reativos quando estimulados a nadar. Os movimentos natatórios voluntários foram recobrados aos cinquenta minutos após a medicação.

TABELA 2. Avaliação dos efeitos de diferentes doses da associação de cloridrato de tiletamina e cloridrato de zolazepam, administrada pela via intramuscular, na anestesia de tilápias-do-nilo (Oreochromis niloticus)

\begin{tabular}{cccccccccccccc}
\hline Trat & Dose & 5 & 10 & 15 & 20 & 25 & 30 & 35 & 40 & $45^{\prime}$ & $50{ }^{\prime}$ & $55^{\prime}$ & $60{ }^{\prime}$ \\
\hline 1 & $5 \mathrm{mg} / \mathrm{kg}$ & 0 & 0 & 0 & 0 & 0 & 1 & 1 & 0 & 0 & 0 & 0 & 0 \\
2 & $10 \mathrm{mg} / \mathrm{kg}$ & 0 & 0 & 0 & 0 & 1 & 2 & 1 & 1 & 0 & 0 & 0 & 0 \\
3 & $20 \mathrm{mg} / \mathrm{kg}$ & 0 & 0 & 0 & 1 & 1 & 2 & 2 & 1 & 1 & 0 & 0 & 0 \\
4 & $30 \mathrm{mg} / \mathrm{kg}$ & 0 & 2 & 2 & 1 & 1 & 1 & 1 & 1 & 1 & 1 & 1 & 0 \\
5 & $40 \mathrm{mg} / \mathrm{kg}$ & 0 & 2 & 2 & 2 & 2 & 2 & 2 & 1 & 1 & 1 & 1 & 1 \\
6 & $60 \mathrm{mg} / \mathrm{kg}$ & 0 & 2 & 2 & 2 & 2 & 1 & 1 & 1 & 1 & 1 & 1 & 1 \\
\hline
\end{tabular}

* Os graus de depressão estão representados pelos números: grau zero - 0 , grau leve -1 , grau moderado -2 , grau severo -3 , anestesia -4 , morte -5 .

Os animais do tratamento 2 , que receberam 10 $\mathrm{mg} / \mathrm{kg}$ da associação anestésica $(0,02 \mathrm{~mL})$, iniciaram perda de reflexos em aproximadamente 23 minutos após receberem a medicação, o que foi evidenciado pela ocorrência de colisões dos peixes contra o vidro do aquário. Tais colisões caracterizaram-se por choques leves, decorrentes dos animais que não conseguiam cessar o nado antes de colidirem com os vidros laterais do aquário de observação. Após trinta minutos apresentaram-se preferencialmente no fundo do aquário, com ausência de movimentos da nadadeira dorsal e redução da reatividade ao estímulo para nadar. Aos quarenta minutos, recobraram o reflexo de retirada e iniciaram movimentação da nadadeira dorsal. 
Os peixes do tratamento 3 receberam $20 \mathrm{mg} / \mathrm{kg}$ da medicação $(0,04 \mathrm{~mL})$. Iniciaram perda de reflexos aos vinte minutos de avaliação. Da mesma maneira que os do tratamento 2, colidiam com os vidros laterais do aquário, demonstrando certa incoordenação do nado. Aos quarenta minutos, apresentavam-se mais responsivos ao meio, recobrando o reflexo de retirada quando estimulados a nadar. $\mathrm{O}$ animal-controle não apresentou nenhuma alteração visível.

Os animais do tratamento 4 receberam $30 \mathrm{mg} /$ $\mathrm{kg}(0,06 \mathrm{~mL})$, projetaram-se para o fundo do aquário aos dez minutos de avaliação, mantendo-se durante dez minutos em decúbito ventral com leve reatividade a estímulos externos, demonstrando movimentos bucais e operculares. A partir do vigésimo minuto, iniciaram movimentação das nadadeiras ventral, caudal e laterais, tornando-se mais reativos ao meio. Ao quadragésimo minuto, recobraram a movimentação de todas as nadadeiras, porém um pouco incoordenados.

Os animais do tratamento cinco receberam 40 $\mathrm{mg} / \mathrm{kg}$ da associação anestésica $(0,08 \mathrm{~mL})$. Ressaltase que por volta de 5 minutos de avaliação apresentaram perda de equilíbrio e ausência dos movimentos da nadadeira dorsal, projetando-se para o fundo do aquário. Do décimo ao trigésimo minuto, permaneceram em decúbito ventral e imóveis no fundo do aquário, sem movimentação de nadadeiras, mantendo apenas os movimentos bucais e operculares. No entanto, quando estimulados a nadar, apresentavam reflexo de ameaça, porém desorientado e incoordenado. A partir de quarenta minutos, voltaram a apresentar movimentação das nadadeiras caudal, ventral e laterais, recobrando a movimentação da dorsal aos cinquenta minutos após a medicação ter sido feita. Destaca-se que, após sessenta minutos, os peixes ainda se mantiveram no fundo do aquário, porém ficaram mais reativos ao meio.

No tratamento 6 , os peixes receberam $60 \mathrm{mg} /$ $\mathrm{kg}$ da medicação $(0,12 \mathrm{~mL})$ dividida em dois sítios de aplicação. Após sete minutos projetaram-se para o fundo do aquário mantendo-se em decúbito ventral. Dos dez aos vinte minutos, observou-se que todos apresentaram ausência da movimentação das nadadeiras e com movimentos operculares mais lentos. A partir de trinta minutos, começaram a recobrar os movimentos das nadadeiras ventral, caudal e laterais, porém mantiveram-se no fundo por mais de sessenta minutos assim como no tratamento 5 .

Dois peixes pertencentes aos grupos 5 e 6 apresentaram perda total dos movimentos, porém, ao serem estimulados, apresentavam movimentos natatório circulares rápidos e incoordenados, permanecendo com sedação moderada por aproximadamente 24 horas após administração da associação anestésica.

Verificou-se a formação de regiões enegrecidas nos locais onde foram feitas as administrações intramusculares das medicações, o que não foi verificado nos animais-controle de cada tratamento, nos quais se aplicou solução salina a $0,9 \%$ (Figura 2). A recuperação dos peixes foi satisfatória, e após 48 horas de experimento houve o desaparecimento das manchas causadas pela associação anestésica.

Todos os tratamentos apresentaram resultados diferentes $(\mathrm{p}<0,001)$ do grupo-controle. Observou-se que o grau de sedação proporcionado pelas doses de 5 e $10 \mathrm{mg} / \mathrm{kg}$ (T1 e T2) foi significativamente inferior ao grau causado pela dose de $40 \mathrm{mg} / \mathrm{kg}$ (T5) (p<0,001 e $\mathrm{p}<0,005$, respectivamente), e que apenas a sedação causada pela dose de $5 \mathrm{mg} / \mathrm{kg}$ (T1) diferenciou-se da de $60 \mathrm{mg} / \mathrm{kg}$ (T6) $(\mathrm{p}<0,01)$.

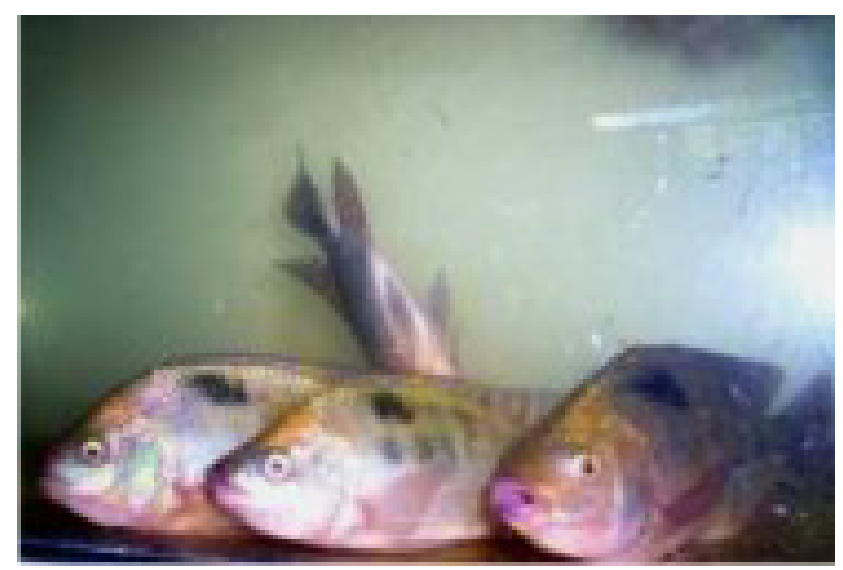

FIGURA 2. Exemplares do tratamento 5 demonstrando a formação de manchas enegrecidas no local da aplicação da associação anestésica pela via intramuscular.

Compararam-se estatisticamente os dados pelo teste de Kruskal-Wallis, com posterior análise pelo teste de Dunn. Valores de p menores que 0,05 foram considerados significativos (Figura 3). 


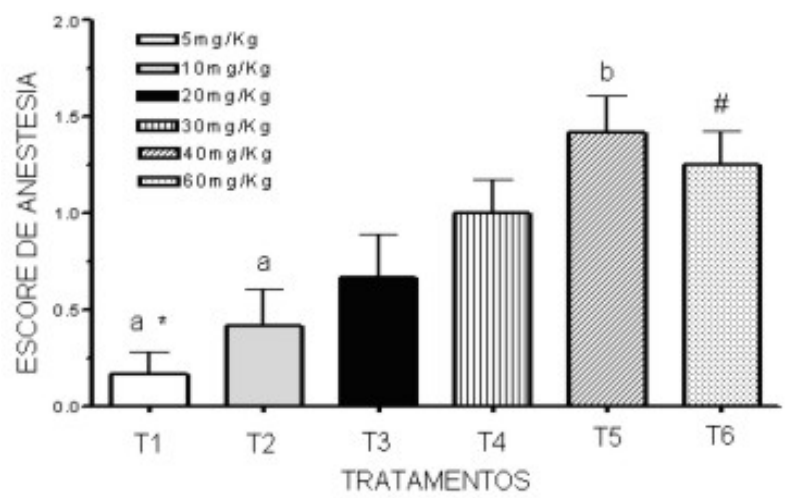

FIGURA 3. Análise estatística dos tratamentos segundo escore de anestesia.

\section{DISCUSSÃO}

O método utilizado com fio de algodão mostrouse efetivo para o período analisado, permitindo total controle na avaliação da reação dos peixes com a medicação recebida. A fixação dos fios de algodão na nadadeira dorsal dos peixes não causou a estes nenhum dano físico, visto que os animais-controle mantiveram todos os reflexos presentes, sem comprometimento funcional do nado.

A maior parte dos protocolos anestésicos em peixes compõe-se de um único agente anestésico, geralmente adicionado à água. Em experimentos com anestesia, BASTOS-RAMOS et al. (1998) utilizaram com sucesso os agentes benzocaína, tiopental e cetamina, assim como BARHAM \& SACHOOMBEE (1991) utilizaram metassulfonato de tricaína (MS-222) diluídos na água.

O uso da via intramuscular em peixes é pouco descrito na literatura. Essa via foi utilizada com sucesso por FLEMING et al. (2003), que testaram protocolos de anestesia parenteral em esturjões do Golfo do México (Acipenser oxyrinchus de soti), utilizando a combinação de propofol intravenoso, com medetomidina e cetamina pela via intramuscular como forma de imobilização rápida dos peixes.

BORIN et al. (2006) verificaram que o uso da associação anestésica Zoletil ${ }^{\circledR} 50$ na dosagem de 7,5 mg/ $\mathrm{kg}$ por via intravascular proporciona anestesia segura de trinta minutos de em tilápias-do-nilo (Oreochromis niloticus), mantidas em ambiente com condições adequadas à espécie. Contraditoriamente, verificou-se com este trabalho que a associação de tiletamina e zolazepam nas dosagens entre 5 e $60 \mathrm{mg} / \mathrm{kg}$ administradas pela via intramuscular não foram efetivas na anestesia tilápias-do-nilo (Oreochromis niloticus).

Através das análises estatísticas pode-se inferir que as doses de 40 e $60 \mathrm{mg} / \mathrm{kg}$ causaram graus de sedação significativamente superiores às demais.

Uma das complicações encontradas foi a limitada capacidade de retenção da medicação pelo tecido muscular dessa espécie, verificando-se que mesmo a aplicação de pequenos volumes resultou em extravasamentos. Embora não tenha havido diferença significativa entre T5 e T6, observa-se que T6 tendeu a apresentar um escore de sedação inferior a T5, mesmo tendo sido realizados dois sítios de aplicação da associação na tentativa de minimizar perdas. Diante disso, sugere-se que doses superiores a $40 \mathrm{mg} / \mathrm{kg}$ da associação de tiletamina e zolazepam não aumentam o grau de sedação, mas o tempo de recuperação dos peixes.

De acordo WALTERMAN \& LUCKE (1992), os efeitos no SNC induzidos pela tiletamina em cães parecem ser dose-dependente. No entanto, mesmo verificando-se que quanto maior a dose mais rápido os peixes demonstravam sedação, não se pode afirmar que os efeitos da associação anestésica sejam dosedependente, devido aos extravasamentos ocorridos nas doses superiores a $30 \mathrm{mg} / \mathrm{kg}$.

Apesar de a combinação do cloridrato de tiletamina (anestésico) e cloridrato de zolazepam (tranqüilizante) ser descrita por possuir ações como catalepsia, analgesia e rápida anestesia sem agitação (THURMON et al., 1996) e efetiva imobilização de vários carnívoros silvestres, aves, répteis e anfíbios (FOWLER \& MILLER, 1986), ela não se mostrou efetiva em tilápias na via e doses testadas, uma vez que os animais estavam reativos a pequenos estímulos. Ressalta-se ainda que nenhum dos animais apresentou decúbito lateral, não atingindo, portanto, estágio de sedação profunda.

GREEN (1979) relata que o início da catalepsia induzida pela injeção intramuscular de tiletamina é rápido e continua por cerca de trinta a cinquenta minutos, dependendo da espécie animal e da dose utilizada. Apesar de a associação anestésica nas doses entre 10 e $60 \mathrm{mg} / \mathrm{kg}$ ter ocasionado sedação de graus leve a moderado após administração IM, sugere-se que 
seu uso seja impróprio para procedimentos cruentos e algésicos, pois nenhuma dessas dosagens foi capaz de causar anestesia.

Sugere-se que os dois animais pertencentes aos tratamentos 5 e 6 , que se apresentaram sedados por 24 horas após receberem a medicação, tenham assimilado maior quantidade de anestésico que os demais, seja por ter havido menor extravasamento da medicação ou maior sensibilidade dos animais aos agentes anestésicos. Desaconselha-se a utilização da associação medicamentosa quando não for possível longa monitoração (pelo menos 72 horas), pois o efeito residual da sedação poderá aumentar a chance de predação dos peixes por outros animais.

\section{CONCLUSÕES}

Verificou-se, neste experimento, que doses de 5 , $10,20,30,40$ e $60 \mathrm{mg} / \mathrm{kg}$ da associação de tiletamina e zolazepam administradas pela via intramuscular são incapazes de causar anestesia em tilápias-do-nilo (Oreochromis niloticus). Ademais, é desaconselhável seu uso por via IM em animais de vida livre ou que não possam ser monitorados por longos períodos, devido ao efeito sedativo residual que pode favorecer a predação.

\section{AGRADECIMENTOS}

Ao Conselho Nacional de Desenvolvimento Científico e Tecnológico (CNPq), pelo financiamento da pesquisa. À médica veterinária Mariana Cristina Hoeppner Rondelli, pela tradução do resumo. Ao médico veterinário Alexandre Pinto Ribeiro, pelo auxílio à análise estatística.

\section{REFERÊNCIAS}

AGORAMOORTHY, G.; RUDRAN, R. Field application of Telazol (Tiletamine hydrochloride and Zolazepam hydrochloride) to immobilize wild red howler monkeys (Alouatta seniculus) in Venezuela. Journal of Wildlife Diseases, v. 30, p. 417-420, 1994.

BACCONI, D. F. Exigências de vitaminas A para alevinos de tilápias-do-nilo Orechromis niloticus. 2003. 42 f. Dissertação (Mestrado em Agronomia, área de Ciência Animal E Pastagem) Universidade de São Paulo, Escola Superior de Agricultura "Luiz de Queiroz", 2003. Disponível em: <http://www.abtilapia.com.br/ arquiv/NutricaoVitamina.pdf>
BARHAM, W. T.; SCHOOMBEE, H. J. A comparison of the effects of alternating current electronarcosis, retified current electronarcosis and chemical anesthesia on the blood physiology of the freshwater bream Oreochromis mossambicus (Peters)-II. The effect on haematocrit, haemoglobin concentration, red cells count, mean cell volume, mean cell haemoglobin and mean cell haemoglobin concentration. Comparative Biochemistry and Physiology, n. 98 A, p. 179-183, 1991.

BASTOS-RAMOS, W. P.; GONÇALVES, N. M. F. M.; BACILA, M. Anesthesia and analgesia in Antarctic fish: an experimental approach. Archives of Veterinary Science, v. 3, n. 1, p. 95-100, 1998.

BORIN, S. ; CRIVELENTI, L. Z. ; LIMA, C. A. P. Avaliação da associação de cloridrato de tiletamina e cloridrato de zolazepam na anestesia em tilápias-do-nilo (Oreochromis niloticus). In: CONFERÊNCIA SUL AMERICANA DE MEDICINA VETERINÁRIA. 6., 2006, Rio de Janeiro. Revista Série Ciências da Vida, Seropédica, RJ : EDUR, v. 26, p. 61-62, 2006.

CUNHA, J. M .C. C. P.; CORTOPASSI, S. R. G.; MACHADO, A. Analgesia trans-operatória induzida pela morfina ou meperidina em gatos submetidos a osteossíntese. Ciência Rural, v. 32, n. 1, p. $67-72,2002$.

DURVILlE, P.; COLLET, A. Clove oil used as an anesthetic with juvenile tropical marine fish. SPC Live Reef Fish Information Bulletin, Saint-Gilles Les Bains, n. 9, p. 17-19, 2001. Disponível em: <http://www.spc.int/coastfish/News/ 1rf/lrf.htm>

FANTONI, D. T.; KRUMENERL JR., J. L.; GALEGO, M. P. Utilização de analgésicos em pequenos animais. Clínica Veterinária, n. 28, p. $23-33,2000$.

FLEMING, G. J.; HEARD, D. J.; FLOYD, R. F.; RIGGS, A. Evaluation of propofol and medetomidine-ketamine for short-term immobilization of Gulf of Mexico Sturgeon (Acipenser Oxyrinchus De Soti), Journal of Zoo and Wildlife Medicine, v. 34, n. 2, p. 153-158, 2003.

FOWLER, M. E.; MILLER, R. E. Zoo and Wild Animal Medicine Current Therapy . Amsterdam: Elsevier Science, 1986. 512 p.

GREEN, C. J. Anesthetic management. In: . Animal anesthesia. London: Laboratory Animals, 1979. p. 85-110.

McFARLAND, W. N.; KLONTZ, G. W. Anaesthesia in fishes. Federation Proceedings, n. 28, p. 1535-1540, 1969.

MEURER, F.; HAYASHI, C.; BOSCOLO, W. R.; SOARES, C. M. Fat on the Reverted Nile Tilápia (Oreochromis niloticus) Fingerlings Feeding. Revista Brasileira de Zootecnia, v. 31, n. 2, p. 566-573, 2002. 
SANTOS, F. G. A.; SALAS, E. R.; BICCA-MARQUES, J. C. et al. Tiletamine hydrochloride in association with zolazepam hydrochloride for the tranquilization and anesthesia of callitrichids. Arquivos Brasileiros de Medicina Veterinária e Zootecnia, v. 51, n. 6, p. 539-545, 1999.

SLADKY, K. K.; SWANSON, C. R.; STOSKOPF, M. K.; LOOMIS, M. R.; LEWBART, G. A. Comparative efficacy of tricaine methanesulfonate and clove oil for use as anaesthetic in red pacu (Piaractus brachypomus). American Journal of Veterinary Research, v. 62, n. 3, p. 337-342, 2001.

SVOBODÁ, M. J.; KOU.IL, J.; HAMÁÃKOVÁ, P.; KALÁB, L. et al. Biochemical profile of blood plasma of tench (Tinca tinca
L.) during pre- and postspawning period. Acta Veterinaria Brno, n. 70 , p. $250-268,2001$.

THURMON, J. C.; TRANQUILLI, W. J.; BENSON, G. J. Lumb \& Jone's veterinary anesthesia. 3. ed. Baltimore: Williams \& Wilkins, 1996. 928 p.

WATERMAN, A. E.; LUCKE, J. N. Anestesia intravenosa. In: HILBERY, A. D. R. Manual de anestesia de los pequeños animales. 3. ed. Zaragoza: Acribia, 1992. p. 45-56.

Protocolado em: 24 jul. 2008. Aceito em: 25 jan. 2010. 